\title{
ESCRITA E TRANSVERSALIDADE: PESQUISADORES INDÍGENAS E A UNIVERSIDADE
}

\author{
AMILTON PELEGRINO DE MATTOS
}

\begin{abstract}
RESUMO
A partir de uma reflexão epistemológica e político-pedagógica centrada em experiências de campo, o texto se propõe pensar a escrita da pesquisa indígena com base em alguns trabalhos de acadêmicos da habilitação de Linguagens e Artes da Licenciatura Indígena da Universidade Federal do Acre. A abordagem dessa escrita é elaborada desde o conceito de transversalidade, conforme proposto por Félix Guattari, e pensado na chamada deste dossiê nos termos da "relação entre saberes heterogêneos enquanto heterogêneos numa experiência de 'transversalidade criativa'". Depois de acompanhar as pesquisas desses acadêmicos entre 2008 e 2018, inclusive em seus desdobramentos fora da universidade, nos campos do cinema ou da arte contemporânea, conclui-se pela especificidade dessa escrita elaborada pelos pesquisadores indígenas, em contraste com a concepção de linguagem, pesquisa e escrita com que a universidade se apresenta a eles.
\end{abstract}

\section{PALAVRAS-CHAVE}

Pesquisa indígena; Escrita; Transversalidade; Linguagens.

\section{WRITING AND TRANSVERSALITY: INDIGENOUS RESEARCHERS AND THE UNIVERSITY}

\begin{abstract}
Based on an epistemological and political-pedagogical reflection centered on field experiences, the text proposes to think about the writing practices of indigenous research based on some works by scholars of the Language and Arts qualification of the Indigenous Pedagogy course at the Federal University of Acre. The approach of this writing is grounded in the concept of transversality, as proposed by Félix Guattari, and addressed in the call of this dossier in terms of the "relationship between heterogeneous knowledge as heterogeneous in an experience of "creative transversality"'. After guiding and monitoring the research of these academics between 2008 and 2018, including their developments outside the university in the fields of cinema or contemporary art, we highlight the specificity of the writing elaborated by the indigenous researchers, in contrast to the conception of language, research and writing with which the university presents itself to them.
\end{abstract}

\section{KEYWORDS \\ Indigenous research; Writing; Transversality; Languages. \\ ÉCRITURE ET TRANSVERSALITÉ: LES CHERCHEURS AUTOCHTONES ETL'UNIVERSITÉ}

\section{RÉSUMÉ}

Basé sur une réflexion épistémologique et politico-pédagogique centrée sur les expériences de terrain, le texte propose de réfléchir aux pratiques d'écriture de la recherche indigène à partir de quelques travaux de chercheurs de la qualification Langue et Arts du cours de Pédagogie Indigène de l'Université Fédéral d'Acre. L'approche de cette écriture est élaborée à partir du concept de transversalité, tel que proposé par Félix Guattari, et pensé par l'équipe de ce dossier en termes de "relation entre des savoirs hétérogènes comme hétérogènes dans une expérience de 'transversalité créative'". Après avoir suivi les recherches de ces universitaires entre 2008 et 2018, y compris leurs développements en dehors de l'université, dans les domaines du cinéma ou de l'art contemporain, nous concluons par la spécificité de l'écriture développée par les chercheurs indigènes, contrairement au concept de langage, de recherche et l'écriture avec laquelle l'université se présente à eux. 


\author{
MOTS-CLÉS \\ Recherche indigène; L'écriture; Transversalité; Langages.
}

\title{
ESCRITURA Y TRANSVERSALIDAD: INVESTIGADORES INDIGGENAS Y LA UNIVERSIDAD
}

\begin{abstract}
RESUMEN
Basado en una reflexión epistemológica y político-pedagógica centrada en experiencias de campo, el texto propone pensar sobre las prácticas de escritura de la investigación indígena basadas en algunos trabajos de académicos de la calificación de Lengua y Artes del curso de Licenciatura Indígena en la Universidad Federal de Acre. El enfoque de este escrito se elabora a partir del concepto de transversalidad, según lo propuesto por Félix Guattari, y reelaborado en la convocatoria de este dossier en términos de "relación entre conocimiento heterogéneo como heterogéneo en una experiencia de 'transversalidad creativa'". Después de guiar y monitorear la investigación de estos académicos entre 2008 y 2018, incluso en sus desarrollos fuera de la universidad, en los campos del cine o el arte contemporáneo, concluimos por la especificidad de la escritura elaborada por los investigadores indígenas, en contraste con la concepción del lenguaje, investigación y escritura con la que se les presenta la universidad.
\end{abstract}

\section{PALABRAS CLAVE}

Investigación indígena; Escritura; Transversalidad; Lenguajes. 


\section{A UNIVERSIDADE}

A Licenciatura Indígena da Universidade Federal do Acre, Campus Floresta (Cruzeiro do Sul), visa atender a demanda dos povos indígenas do estado e seus professores, que atuam há mais de três décadas nas escolas das comunidades. Muitos deles têm sua formação em níveis fundamental e médio em cursos específicos oferecidos esporadicamente pela Secretaria de Educação do Estado.

A Licenciatura Indígena teve seu primeiro processo seletivo em 2008 com duas turmas, totalizando pouco mais de 50 alunos. Essa primeira etapa foi composta de acadêmicos dos povos Puyanawa, Manchineri, Jaminawa, Huni Kuin, Shanenawa, Katukina, Yawanawa, Ashaninka, Shawandawa, Nukini, Nawa e Marubo. Com a formatura dessas duas primeiras turmas, essa etapa foi finalizada em 2013. Depois de uma interrupção nas atividades do curso, ocorreu um processo seletivo em fins de 2016, com o ingresso de duas novas turmas. Essa etapa, iniciada em 2017 e em andamento, encontra-se interrompida pela pandemia da Covid-19.

Ingressei como professor na Licenciatura em 2008, três anos depois de ter concluído o mestrado em Educação na Universidade de São Paulo, com pesquisa em educação escolar indígena e trabalho de campo realizado entre os Guarani M'byá e Kaoiwá (MATTOS, 2005). Vivendo no Acre desde 2004, antes de compor o quadro do curso atuava pela Secretaria de Educação do Estado assessorando escolas indígenas da região do vale do rio Juruá, em Cruzeiro do Sul.

Passei a compor o quadro docente da Licenciatura Indígena na área de Linguagens e Artes. Conforme o Projeto Pedagógico de Curso (UFAC, 2007; UFAC, 2015), a Licenciatura é organizada em módulos e por alternância: com atividades que se desenvolvem na universidade (fase presencial) e atividades que têm lugar nas comunidades (fase intermediária), quando os acadêmicos recebem os professores da universidade em suas aldeias. O percurso é dividido em "núcleo comum" e "estudos aprofundados", a partir dos quais os acadêmicos se distinguem por habilitações, onde se concentram as pesquisas e a elaboração de Trabalhos de Conclusão de Curso (TCC). Além da formação propriamente pedagógica, o curso se constitui das três áreas que definem habilitações: Linguagens e Artes, Humanidades e Ciências.

A pesquisa, além de importante componente nos documentos oficiais sobre educação escolar indígena (BRASIL, 1998) e formação de professores indígenas (BRASIL, 2015), tem um papel central no projeto do curso. Ela articula tanto o eixo que o divide em fases presencial e intermediária, quanto o eixo que separa o percurso em núcleo comum e estudos aprofundados. A pesquisa é tanto procedimento de formação quanto recurso didático na prática desses professores. Para isso, os acadêmicos realizam as pesquisas da 
etapa comunitária com atividades que envolvem a escola e outros segmentos da comunidade. Esse processo proporciona uma formação que articula docência e pesquisa, tanto quanto universidade e aldeia, com seus distintos regimes de conhecimento.

\section{DESENCONTRO DE LINGUAGENS}

Este texto trata do problema da constituição de uma concepção de língua e linguagem específica, descrita a partir da experiência de pesquisa de acadêmicos de uma licenciatura indígena. Essa concepção de linguagem emerge no encontro e na relação desses acadêmicos com as noções de linguagem e de conhecimento da universidade. A abordagem do problema se caracteriza como um esforço para pensar o encontro desde a experiência da transversalidade, isto é, da relação entre saberes heterogêneos enquanto heterogêneos.

Considerando a importância desse encontro entre diferentes concepções de língua e linguagem, o objetivo do texto é realizar uma série de relatos etnográficos dos encontros e desencontros desses agentes, indígenas e universidade, vistos desde experiências apreendidas em práticas de ensino e pesquisa da Licenciatura Indígena da UFAC - Floresta, com destaque para as práticas de escrita nas pesquisas desses acadêmicos, inclusive aquelas que se estendem em projetos comunitários. Como essa etnografia se dispõe ao longo de dez anos de experiência aproximadamente, adianto que vou destacar momentos específicos: (1) um primeiro momento, quando o curso tem início; (2) os semestres que seguem, com as práticas de pesquisa; (3) a partir de 2014-15, depois da formatura e finalização dos TCCs, quando desenvolvo atividades com Tene e Ibã, enquanto participo da reelaboração de um projeto de curso.

Nesses relatos, pretendo enfocar o contraste entre a concepção de linguagem da universidade, em relação de pressuposição recíproca com os princípios epistêmicos e ontológicos do pensamento científico moderno, e a concepção de linguagem elaborada a partir das experiências de pesquisa dos acadêmicos indígenas e dos conhecimentos produzidos com base nelas.

A relação definida pela transversalidade, ao destacar a diferença, permitirá colocar, assim, o problema da escrita nas práticas de pesquisa que serão abordadas. A pesquisa e sua escrita tiveram um papel fundamental para que os acadêmicos tivessem condições de, desde sua posição minoritária, colocar nesse encontro a sua diferença via uma concepção de linguagem própria. Assim, o problema da escrita das pesquisas, em que nos envolvemos diferentemente acadêmicos e orientadores, suscitaria uma questão central: em que consistiria uma concepção de linguagem outra?

Entendo transversalidade aqui como um esforço para afirmar a potência desestabilizadora da diferença (GOLDMAN, 2008; 2006, p. 264) frente a instituições e 
segmentos que atuam policiando e neutralizando a diferença, redistribuindo-a nos termos dos conhecidos operadores de homogeneização: natureza e cultura, indivíduo e sociedade, realidade e representação (VIVEIROS DE CASTRO; GOLDMAN, 2012; GOLDMAN, 1999). O conceito de transversalidade funcionará então para destacar as conexões rizomáticas (DELEUZE; GUATTARI, 2011) com que essas pesquisas buscam escapar à neutralização da diferença e do Outro, operada pelos divisores e seu regime de signos (cf. infra).

Em suma, o problema que este texto coloca é como pensar a prática de pesquisa e escrita indígena na universidade tanto quanto (e/ou em relação com) a experiência de ensino, orientação de pesquisas, e ainda a formulação de um projeto de Licenciatura Indígena na área de Linguagens e Artes, a partir da questão: em que consiste, afinal, uma língua?

Essa questão foi sendo diferentemente recolocada para mim ao longo de anos de acompanhamento e participação nesse encontro entre academia e indígenas à medida que discernia e percebia se articularem distintas concepções de linguagem. A partir da experiência desse confronto entre concepções de linguagem, procuro descrever suas estratégias de enfrentamento e modos de relação.

No modo de relação proposto pela universidade está implicado um conceito de língua concernente ao seu regime de conhecimento, com os divisores típicos da ontologia naturalista que ele supõe universal. A pressuposição de uma universalidade da Natureza media a relação entre a concepção de linguagem da universidade e a maneira como ela se dispõe ao encontro, seu modo de se relacionar com o Outro e seus saberes, mesmo ou principalmente quando se trata de saqueá-los (CLASTRES, 1968; VIVEIROS DE CASTRO, 2015).

Visando evitar um reducionismo ao generalizar o que chamo de concepção de linguagem e conhecimento da universidade, remeto aos contrastes elaborados por Wagner (2010) e Viveiros de Castro (2002). Buscando distinguir e contrastar esses modos de conhecer e a concepção de linguagem que eles implicam, escreve Wagner:

\begin{abstract}
"A produtividade das sociedades tribais não é obcecada por instrumentos ou técnicas na medida em que constitui uma parte das relações interpessoais e encarna valores humanos e não valores abstratos. (...) Assim, as culturas tribais encarnam uma inversão de nossa tendência a fazer das técnicas produtivas o foco das atenções e a relegar a vida familiar a um papel subsidiário (e subsidiado). Essa inversão não é trivial: ela permeia ambos os estilos de criatividade em todos os seus aspectos. Na medida em que produzimos "coisas", nossa preocupação é com a preservação de coisas, produtos, e com as técnicas de sua produção. Nossa Cultura é uma soma dessas coisas: conservamos as ideias, as citações, as memórias, as criações, e deixamos passar as pessoas. Nossos sótãos, porões, baús, álbuns e museus estão repletos desse tipo de Cultura" (2010, p. 60).
\end{abstract}

Compare-se essa passagem ao trecho em que Viveiros de Castro também compara os regimes de conhecimento e linguagem moderno e ameríndio. 
"O xamanismo é um modo de agir que implica um modo de conhecer, ou antes, um certo ideal de conhecimento. Tal ideia é, sob vários aspectos, o oposto polar da epistemologia objetivista favorecida pela modernidade ocidental. Nesta última, a categoria do objeto, fornece o telos: conhecer é objetivar; é poder distinguir no objeto o que the é intrínseco do que pertence ao sujeito cognoscente, e que, como tal, foi indevida e/ou inevitavelmente projetado no objeto. Conhecer, assim, é dessubjetivar, explicitar a parte do sujeito presente no objeto, de modo a reduzi-la a um mínimo ideal. Os sujeitos, tanto quanto os objetos, são vistos como resultantes de processos de objetivação: o sujeito se constitui ou reconhece a si mesmo nos objetos que produz, e se conhece objetivamente quando consegue se ver "de fora", como um "isso". Nosso jogo epistemológico se chama objetivação; o que não foi objetivado permanece irreal e abstrato. A forma do Outro é a coisa. O xamanismo ameríndio parece guiado pelo ideal inverso. Conhecer é personificar, tomar o ponto de vista daquilo que deve ser conhecido - daquilo, ou antes, daquele; pois o conhecimento xamânico visa um "algo" que é um "alguém", um outro sujeito ou agente. A forma do Outro é a pessoa" (2002, p. 358).

Como se percebe em ambos os textos os diferentes modos de conhecimento supõem igualmente diferentes concepções de linguagem. Considero que a concepção moderna de língua/linguagem, em relação de pressuposição recíproca com uma determinada imagem do pensamento, foi bem definida a partir daquilo que Deleuze e Guattari (1995) chamaram, em Mil platôs, de postulados da Linguística. São quatro os postulados que sustentariam a imagem moderna que fazemos da linguagem verbal: 1) a linguagem seria informativa e comunicativa; 2) haveria uma máquina abstrata da língua, que não recorreria a qualquer fator extrínseco; 3) haveria constantes ou universais da língua que permitiriam defini-la como um sistema homogêneo; 4) só se poderia estudar cientificamente a língua sob as condições de uma língua maior ou padrão.

Não é o caso de abordar aqui cada um desses aspectos. Eles me servirão assim, em bloco, para estabelecer um contraste entre a concepção de linguagem moderna, pressuposta na escrita acadêmica, e aquela outra concepção de linguagem que pretendo demonstrar que emergiu das práticas de pesquisa e escrita dos acadêmicos do curso.

Assim, tal como a imagem da língua, diferente também é o "modo da relação" nas práticas dos acadêmicos indígenas, que estão em posição minoritária. Suas práticas parecem não compartilhar dos pressupostos da relacionalidade moderna. Longe de se identificarem e isolarem em seus saberes, colocam-se à disposição do encontro, apropriando-se dos recursos de linguagem da universidade, tais como escrita e pesquisa, e os valorizando. No entanto, ao colocarem esses recursos à prova de práticas de linguagem típicas de seu regime de signos, voltando-se para o estudo de rituais, cantos ou grafismos, essas pesquisas elaboram "escritas" que supõem a multiplicidade em vez da natureza unificada e seu duplo, o multiculturalismo ou a "interculturalidade" (VIVEIROS DE CASTRO, 2002; 2015, p. 115; DELEUZE; GUATTARI, 2011; MATTOS, 2019).

Seu modo de relação com a universidade não difere assim daquele que define a "socialidade" ou "política" ameríndia e o xamanismo inerente a elas: os saberes vêm de fora, 
apreendidos de alteridades poderosas (animais, espíritos ou inimigos), constituindo-se em práticas de produção de corpos de "humanos verdadeiros" (os rituais), a humanidade intensiva daqueles que "comigo fazem corpo" (VIVEIROS DE CASTRO, 2002; LAGROU, 2007, 2011; KENSINGER, 1991). O próprio modo da relação com a universidade, inclusive, deve ser compreendido a partir desse regime de conhecimentos. Assim, as práticas de linguagem próprias a esse regime de conhecimento (rituais, mitos, cantos e danças) redefinirão o "centro de gravidade" da pesquisa e suas escritas (COLLET, 2006).

Em lugar de "registrar" na forma acadêmica um conteúdo indígena, essas pesquisas se colocam em relação de coplanaridade com tais práticas de linguagem, centradas na sociocosmologia multinaturalista e nas transformações corporais, para elaborar seus experimentos de escrita. Coplanaridade é como chamo a maneira como algumas das pesquisas que acompanhei na Licenciatura Indígena compõem com as práticas de linguagem (cantos, rituais, grafismo) que estudam, engajando pessoas e constituindo coletivos que entendem esses processos de investigação em continuidade com tais práticas de produção de corpos ou atualização de redes relacionais com pessoas não humanas (VIVEIROS DE CASTRO, 2002, 2015; COLLET, 2006).

Como se verá adiante, tal coplanaridade conduzirá ainda, por esse outro modo da relação, a um fenômeno de diferenciação quanto ao saber acadêmico, dando lugar à reivindicação de uma "pesquisa indígena", como atesta o caso da "pesquisa huni kuin". Porém, é antes por uma dedicação e mesmo um engajamento visceral na pesquisa por parte desses acadêmicos, e não por deixá-la de lado, numa atitude de verticalismo hierarquizante, que se torna cada vez mais elaborada essa outra concepção de linguagem.

A noção de coplanaridade, conforme utilizada por Viveiros de Castro (2015, p. 260), refere-se originalmente a um determinado modo da relação entre o pensamento antropológico e o pensamento dos povos que ele estuda, modo esse inspirado na "abertura ao Outro" que caracterizaria justamente o pensamento ameríndio, segundo Lévi-Strauss (1993). Coplanaridade consistiria então no ato da disciplina de estabelecer ou "traçar um plano de imanência comum a seu objeto", ou seja, no esforço para pensar a relação como experiência de transversalidade.

\section{A LÍNGUA DA UNIVERSIDADE}

Ao iniciar as atividades no curso em 2008 com a disciplina de Língua portuguesa, propus aos estudantes um debate inicial visando mapear o uso das línguas indígenas e da língua portuguesa nas aldeias. A disciplina realizou assim o mapeamento da situação heterogênea das línguas e promoveu uma troca de experiências entre os acadêmicos a respeito de suas comunidades quanto ao uso da língua e seus projetos de política linguística. 
Essa troca de experiências, além de ter sido uma maneira de integrar os acadêmicos, foi importante para que, tanto eles como eu, tomássemos conhecimento de como as comunidades pensam as línguas, seu ensino e ainda como as escolas se organizam a partir disso.

Paralelamente, em uma das primeiras reuniões de colegiado que tivemos, alguns colegas relataram sua dificuldade com o desempenho dos acadêmicos na leitura e escrita de textos e trataram que o curso de Língua portuguesa deveria se preocupar com tal defasagem. Como eles se refeririam aos acadêmicos indígenas nos termos de uma deficiência, sugeri pensarmos estratégias que considerassem uma ideia mais plural de texto, referindo-me à importância de uma abertura para outras maneiras de se entender e trabalhar a linguagem. Eles insistiram, porém, em que a disciplina Língua portuguesa deveria se empenhar em "ensinar aos alunos indígenas a ler e escrever", suprindo assim "deficiências" entendidas segundo uma competência individualizada.

A opção por etnografar a atitude desses professores da universidade, que apenas provisoriamente ministravam disciplinas da área de ciências da natureza e que viviam sua primeira experiência com povos indígenas, deve-se ao fato de ela retratar uma ideia moderna de linguagem pressuposta na universidade que vai se repetir em uma série de outros exemplos. Outro exemplo da força dessa imagem da língua consiste nos inúmeros relatos de preconceitos sofridos na universidade por esses acadêmicos. Tal imagem da língua serve aqui, sobretudo, para contrasta-la com a noção de linguagem que baseará as práticas de pesquisa e escrita dos acadêmicos do curso ao longo dos anos seguintes. Buscarei aprofundar esse contraste ao longo do texto ao articular os diferentes regimes de conhecimento às diferentes concepções de linguagem.

Tal ideia de linguagem dos meus colegas não tardaria a chegar aos acadêmicos, que me questionaram se eu os ensinaria essa língua que lhes era exigida, uma ideia de língua da universidade, à qual seu processo formativo não lhes teria dado acesso até então. Também me colocaram a demanda de torná-los aptos a levar essa ideia de língua portuguesa para seus alunos, nas escolas das aldeias. Em resposta à primeira demanda, inseri no programa aulas de morfossintaxe. Quanto ao ensino de língua portuguesa na escola indígena, concluímos o mapeamento das práticas de linguagem das comunidades enfocando, com a colaboração dos professores mais experientes, as práticas de ensino de língua portuguesa e línguas indígenas.

Hoje me chama atenção que, seja em minha proposta mais sociolinguística, seja no tipo de competência exigida por meus colegas, variávamos entre os polos de um dos divisores centrais da Linguística: aquele que distingue indivíduo e sociedade. $\mathrm{E}$ isso retrospectivamente, pois a linha de fuga que será proposta pelos acadêmicos ao iniciarem 
suas pesquisas encontrará em suas práticas de linguagem (rituais, cantos, grafismos) uma mereologia (VARZI, 2019) própria de seu regime de signos.

Terminada a disciplina de Língua Portuguesa, começamos a planejar as pesquisas a serem realizadas na fase intermediária. A partir desse momento os acadêmicos passaram a ter contato com uma metodologia ainda menos expositiva e cada vez mais centrada em seus próprios problemas. Eles começariam a realizar suas pesquisas enfocando práticas de linguagem de suas comunidades e povos, o que redefiniria esse encontro com a universidade e com essa sua concepção de linguagem.

\section{XAMANIZAR A PESQUISA}

Seguindo com a experiência na Licenciatura indígena, desde o primeiro semestre, quando passamos a planejar os projetos de pesquisa ou planos de atividade para o retorno dos acadêmicos para suas comunidades, as pesquisas colocaram desde outra perspectiva o problema da linguagem e de seu ensino. Começaram por possibilitar o intercâmbio de práticas de investigação e de "ensino via pesquisa" entre os acadêmicos, cujas experiências descreviam as mais heterogêneas situações de uso das línguas. De aulas mais expositivas, passamos a uma dinâmica descentralizada, em que esses acadêmicos cada vez mais trocavam

e conduziam problemas em torno das próprias práticas. Essa dinâmica favoreceu a elaboração de uma concepção de linguagem própria, em lugar da busca por enquadrar-se na ideia de competência linguística que a universidade lhes exigia.

As primeiras atividades de pesquisa na área de Linguagens e Artes foram os planejamentos para a etapa comunitária que se seguiria nesse primeiro semestre com as disciplinas de Ensino de Artes e Produção de Material Didático. Essas práticas nas comunidades tiveram a colaboração de anciãos, de lideranças, dos professores, da comunidade escolar, dos grupos de jovens, de outros especialistas. Consistiriam em atividades coletivas que tratavam quase sempre de saberes e práticas entendidos como "culturais".

Como resultado dessa primeira experiência em campo, os acadêmicos e eu montamos uma exposição no museu da cidade com objetos que apresentavam as técnicas e práticas de seus povos, tais como armas de caça, tecelagem e cerâmica. Também realizamos uma mostra de cinema indígena com três noites de debate, com a participação de realizadores indígenas e outros convidados. No terceiro dia foi oferecida uma caiçumada (distribuição de bebida de mandioca fermentada) para os participantes.

Em vez de espaço de narrativa sobre o passado e a cultura, o museu histórico foi apropriado pelos acadêmicos indígenas como espaço performático. Essa apropriação performática do museu, com direito a caiçuma, foi acentuada com a mostra de filmes 
indígenas, inclusive filmes dirigidos por acadêmicos do curso, evidenciando ainda a associação dos conhecimentos indígenas às tecnologias digitais.

Se apresentar seus conhecimentos no museu, no cinema ou na universidade pode ser entendido na chave da cultura, como revitalização cultural, era claro também que se tratava de oportunidade de atualizar esses saberes e práticas (COLLET, 2001). Tal atualização era dada a ver pelos efeitos dessas intervenções nas comunidades, que se engajaram nas pesquisas, mas também pela relação de coplanaridade entre as pesquisas e os saberes e práticas indígenas. Assim, o próprio meio "museu", de espaço expositivo, tinha sido xamanizado, isto é, apropriado em função da transformação e da atualização ameríndias.

O título desta seção faz referência a um artigo de Silvia Macedo intitulado "Xamanizando a escrita" (2009), em que a autora vai pensar a atribuição de sentido e a incorporação da escrita entre povos ameríndios a partir de sua relação com o xamanismo. Tomando como referência sua experiência junto aos Wayãpi, ela explica a relação entre grafismo, que transforma corpos humanos e objetos, e escrita, denominados igualmente de kusiwa. É a partir do contato entre a escrita e o caráter transformacional do grafismo, próprio ao regime de conhecimento xamânico, que se daria essa xamanização da escrita, que, afetada por uma ontologia transformacional, perderia seu valor representacional. Essa noção de xamanismo adotada pela autora é a mesma definida por Viveiros de Castro como um "modo de conhecer" baseado na habilidade de cruzar fronteiras transespecíficas visando realizar as traduções necessárias a uma diplomacia cósmica.

Conforme Macedo apresenta o processo de xamanização da escrita, que perde seu caráter representacional ao ser afetada por uma ontologia transformacional, também o museu, para usar as expressões de Wagner (2010, p. 55) para contrapor igualmente duas semióticas, de "instituição cultural", onde os modernos preservam, segundo as demandas da convenção, as imagens de seu processo de refinamento, seria subvertido pela apropriação visando a "produção de pessoas", processo marcado, entre outros exemplos, pelo compartilhamento da caiçuma (bebida de mandioca preparada pelas mulheres) com os brancos da universidade.

Se esses eventos tiveram um forte impacto na comunidade acadêmica e foram um momento importante nesse primeiro encontro de indígenas e universidade, também meu modo de compreender suas pesquisas foi bastante impactado por essa experiência. Pude perceber então, desde esse primeiro momento, especialmente para a área de artes, que as pesquisas atualizavam mais do que representavam os saberes com que elas compunham, traçando assim um plano de imanência comum, no qual uma e outros estão em continuidade. Isso implicava em uma pesquisa segundo a qual conhecer consiste em engajar pessoas e coletivos, transformar corpos, atualizar redes relacionais com não humanos. 
No entanto, mesmo que retrospectivamente seja possível notar desde o primeiro semestre esse aspecto central da pesquisa que busco destacar aqui, foi nos semestres seguintes, à medida que nos dedicamos mais às investigações, que as práticas de linguagem e conhecimento indígenas se evidenciaram ainda mais como procedimento de pesquisa.

Nos semestres que se seguiram, realizamos em disciplinas dedicadas aos TCCs uma série de atividades nas quais um pesquisador da turma conduzia uma sequência de aulas a partir de suas práticas. Uma dessas atividades incluiu a visita à Terra Indígena Puyanawa, quando o professor Maná Huni Kuin (MANÁ, 2013), da Terra Indígena do Rio Breu, que investigava o katxa nawa, ritual huni kuin da fertilidade das plantas cultivadas, propôs orientar as turmas em uma prática de canto e dança dessa cerimônia. Depois de cantar e dançar, a turma se reuniu a Maná na casa cerimonial da aldeia para um debate a respeito da experiência e da pesquisa.

Tene Huni Kuin (TENE, 2013) conduziu uma série de atividades junto à turma em torno de sua experiência de pesquisa do nixpu pima, ritual de iniciação huni kuin. A partir das questões referentes ao diálogo com os mais velhos, suscitadas na apresentação de seu trabalho, ele orientou os colegas em atividades de entrevista, nas quais foram elaboradas perguntas depois dirigidas aos pesquisadores mais experientes da turma a respeito de seus trabalhos. Essas entrevistas foram também registradas em vídeo por eles, visando a experiência com o audiovisual.

Em outra série de atividades, Ibã Huni Kuin (2006; MATTOS; IBÃ, 2015) apresentou sua pesquisa com os huni meka (cantos de ayahuasca) e narrou a gênese do coletivo Mahku Movimento dos Artistas Huni Kuin, grupo de jovens huni kuin que se juntaram a ele em seu estudo para realizar a transposição desses cantos para o desenho e a pintura. Ele também apresentou as experiências em audiovisual feitas junto ao Laboratório de Imagem e Som da Licenciatura Indígena da UFAC - Floresta, vídeos nos quais Ibã executa e comenta os cantos a partir dos desenhos ${ }^{2}$.

Foi com esses procedimentos didáticos, acompanhados das atividades nas comunidades, que as pesquisas trouxeram outras referências para o debate e para as práticas. Iniciava-se definitivamente a elaboração de uma outra concepção de língua e linguagem, influenciada cada vez mais pelo regime de signos que predomina em seus conhecimentos e suas práticas de linguagem. Como se tratava de um exercício estritamente prático, só percebi esse contraste entre diferentes concepções de linguagem à medida que acompanhava a prática dessas pesquisas e os problemas específicos de escrita que elas

\footnotetext{
${ }^{1}$ As etapas que seguem foram longamente descritas e analisadas em Mattos (2021).

${ }^{2}$ Disponível em: www.youtube.com/watch?v=plo90b2qGDI\&t=211s. Acesso em junho de 2020.
} 
colocavam, assim como os processos de transformação vividos pelos acadêmicos. Nesses processos, eu mesmo era constantemente chamado a me engajar, por meio da elaboração de projetos ou de atividades audiovisuais, principalmente quando estava em campo para as etapas comunitárias.

Conforme apresentei, a pesquisa é um importante elemento curricular e instrumento metodológico no projeto do curso. A prática da pesquisa de conhecimentos que são entendidos como "culturais" e a produção de materiais didáticos específicos são elementos constituintes da escola indígena. Desse modo, também em suas práticas de ensino, com o uso de seu idioma em muitos casos, esses acadêmicos registram com seus alunos cantos e rituais junto aos mais velhos, transcrevendo suas memórias e fazendo da escola e de sua docência o campo de circulação e atualização desses conhecimentos, seguindo um caminho que pode ser chamado de cultural ou intercultural.

Por outro lado, apropriada pelos acadêmicos, a pesquisa parece percorrer outro caminho que esse que denominamos de cultural. Trata-se do percurso daqueles conhecimentos ou recursos adquiridos de alteridades não humanas, um genro/sogro animal ou um yuxibu (espírito forte) de quem em geral se rouba o conhecimento para trazer a novidade para o seu povo, conforme narrado em tantos mitos dos povos da região (LÉVISTRAUSS, 2004b; LAGROU, 2007; MATTOS, 2019). Assim, como é próprio a esse pensamento, a pesquisa e sua escrita, como todo evento ou "novidade", acomodam-se ou atualizam esse regime de conhecimentos, encontrando lugar em suas práticas (LÉVI-STRAUSS, 2010, p. 29; 2004a, 1993). A pesquisa é assim incorporada e passa a operar segundo a lógica de um outro regime de signos. Esse regime de signos se define pela transformação de corpos-pessoas instáveis desde uma "humanidade intensiva", em contraste com aquele que se define pela representação de um mundo estabilizado pela ciência na ideia de natureza, da qual a humanidade se teria "separado" justamente com a emergência da linguagem verbal (SAHLINS, 2007; VIVEIROS DE CASTRO, 2002; COLLET, 2017).

Remeto ao conceito de regime de signos elaborado por Deleuze e Guattari (1995; GOLDMAN, 1999) visando dar conta da transversalidade conforme ela se apresenta na relação entre esses diferentes conjuntos de pressupostos epistemológicos e ontológicos confrontados nesse encontro de saberes. A noção de regime de signos é que vai também possibilitar tratar o problema de escrita suscitado pela pesquisa indígena e a concepção de linguagem que ela coloca em jogo.

Um dos objetivos da adoção do conceito de regimes de signos é marcar que com as pesquisas indígenas e suas conexões transversais já não mais nos deslocamos exclusivamente no regime de signos que associo à universidade, a que os autores se referem como "regime de signos significante" (DELEUZE; GUATTARI, 1995, p. 64-103). Esse regime se define pela seguinte fórmula: "o signo remete ao signo tão somente e infinitamente". Рara 
circunscrever esse regime como um entre outros, os autores afirmam a importância de uma pragmática, "na qual a linguagem nunca possui universalidade em si mesma, nem formalização suficiente, nem semiologia ou metalinguagem gerais" (Ibid., p. 64).

Um regime de signos pode ser entendido como "mais e menos do que a linguagem", isso porque "há sempre uma forma de conteúdo, simultaneamente inseparável e independente da forma de expressão" (DELEUZE; GUATTARI, 1995, p. 63-64). Рara eles, é difícil considerar esses regimes ou semióticas nelas mesmas.

"Os regimes de signos se definem, assim, por variáveis interiores à própria enunciação, mas que permanecem exteriores às constantes da língua e irredutíveis às categorias linguísticas. Mas, nesse ponto, tudo bascula, e as razões pelas quais um regime de signos é menos do que a linguagem devêm razões pelas quais, igualmente, ele é mais do que a linguagem. O agenciamento só é enunciação, só formaliza a expressão, em uma de suas faces; em sua outra face inseparável, ele formaliza os conteúdos, é agenciamento maquínico ou de corpo" (p. 103).

O conceito de regime de signos reestabeleceria as duas faces inseparáveis do agenciamento que o regime significante supõe como ontologicamente diferentes. Os agenciamentos que definem os regimes de signos se articulam em duas faces inseparáveis e em relação de pressuposição recíproca (DELEUZE; GUATTARI, 1995, p. 102-3): agenciamentos de enunciação e agenciamentos maquínicos (de corpos).

Essa outra imagem da pesquisa, melhor compreendida a partir do mito e do ritual, recursos fundamentais desse regime de conhecimentos, aponta desde já para a problematização das coordenadas que definem o conhecimento moderno da universidade e sua concepção de linguagem: os divisores indivíduo/sociedade, realidade/representação e natureza/cultura, que começam por dividir os conhecimentos em ciências naturais e ciências do espírito. À medida que os pesquisadores indígenas passam a manejar uma outra concepção de linguagem, também o conhecimento elaborado por esses trabalhos corta transversalmente esses divisores com conexões rizomáticas. Com isso, a lógica do multiculturalismo e da interculturalidade colocada em campo pelo discurso oficial, e que acaba fazendo da universidade e da Licenciatura Indígena uma espécie de armistício epistemológico, vai conhecer um outro campo de batalha. A epistemologia (política) é a ontologia (guerra) por outros meios.

Em suma, a estratégia dessa pesquisa consiste em se apropriar da prática científica, colocando-a à prova de um regime de signos alheio, de modo a bloquear a neutralização da produção de diferença. Essa neutralização da diferença, que é função dos divisores, como no caso da cultura e da interculturalidade, é então bloqueada por uma operação que começa na coplanaridade que a pesquisa indígena estabelece com práticas de linguagem tais como o mito e o ritual (LÉVI-STRAUSS; ERIBON, 2005, p. 150; VIVEIROS DE CASTRO, 2015, p. 260). Isso é o que chamo de transversalidade neste trabalho: liberar a produção da diferença ao bloquear seus inibidores. 
Em lugar de conteúdos a serem veiculados nas pesquisas, esses saberes passaram a operar também como práticas, portanto, em um mesmo plano. Foi assim que essas práticas de linguagem (rituais, cantos ou mitos) passaram de tema à própria forma com que a pesquisa se apresenta. É também isso que chamo aqui de coplanaridade: em vez do registro de um canto, o próprio canto passa a se apresentar como pesquisa. Em vez de um trabalho que fala a respeito ou descreve um ritual, o engajamento na realização de um ritual que se apresenta ele próprio como pesquisa. O que não contradiz a extensão ou acoplamento de um (pesquisa, descrição, análise, estudo) a outro (realização do ritual, execução coletiva do canto, performance do mito na comunidade) (cf. infra).

Foi assim então que muitos desses trabalhos tiveram papel fundamental na transformação desses pesquisadores, à medida que a aquisição dos conhecimentos xamânicos próprios a esse regime de signos quase sempre redunda em um processo de transformação daquele que adquire esses conhecimentos. Ao concluir a pesquisa de determinado ritual, o pesquisador acaba por se tornar uma referência ou mesmo o responsável na comunidade por esse ritual. Ou o inverso: muitos desses acadêmicos, ao chegarem à universidade, já se apresentavam ou eram reconhecidos por sua comunidade como estando em preparação para se tornarem responsáveis por determinado saber ou ritual.

Com isso se percebe que essa pesquisa passa a ser xamanizada, a operar segundo um regime de signos que, ainda que se utilize de, não se baseia apenas no registro, no armazenamento, na interpretação, na representação, priorizando, em vez disso, a conexão, a relação, a transformação (MACEDO, 2009; COLLET, 2017). Um regime de signos, mesmo que exerça um domínio relativo sobre outro, não o exclui (DELEUZE; GUATTARI, 1995, p.74).

\section{PROBLEMA DE ESCRITA}

De maneira similar a outros povos da família linguística Pano, os Huni Kuin denominaram em seu idioma a escrita alfabética pelo termo kene, nome que dão a seu repertório de grafismos, desenhos bastante elaborados com que recobrem, marcando e transformando, corpos humanos e corpos de objetos (COLLET, 2006; LAGROU, 2007; DÉLÉAGE, 2017; CESARINO, 2012). Da mesma maneira, sobrepondo diferentes regimes de signos, usam em português a palavra escrita para denominar tais grafismos, referindo-se aos kene como "nossa escrita" e os associando à escrita dos brancos.

Essa noção de escrita com que esses povos incorporam seus sistemas gráficos parece se referir a uma relação entre palavras (agenciamentos de enunciação) e corpos (agenciamentos maquínicos) própria de seu regime de signos. Trata-se de uma escrita que, em vez de representar os corpos (humanos e não humanos), agiria para transformá-los. Tais 
ideias, que foram tema de um diálogo de Clastres (2003) com Deleuze e Guattari (2010, 1997; COLLET, 2017; LAGROU, 2011), servirão de referência para pensar a especificidade da escrita das pesquisas de Tene e Ibã. Como se verá, essa escrita opera em continuidade com suas práticas de linguagem (rituais, cantos e danças, mitos, grafismos) da mesma forma que em conexões rizomáticas com o cinema ou a arte contemporânea (MATTOS; IBÃ, 2016a, 2016b).

Como orientador, acompanhei Tene na realização de seu TCC dedicado ao nixpu pima, rito de iniciação dos jovens huni kuin. Sua monografia consistiu na compilação de cantos do ritual, no registro de um mito que narra a origem do rito de iniciação e de seus cantos, na transcrição de memórias de anciãos sobre a prática da cerimônia no passado, e ainda inclui o relato de seu percurso junto com sua família na realização da pesquisa (TENE, 2013).

Além disso, desde 2011 nós dois já vínhamos elaborando e submetendo um projeto destinado à realização desse ritual e seu registro audiovisual na aldeia Flor da Mata, comunidade de Tene localizada no território huni kuin do alto rio Tarauacá. Em 2014, com a liberação do recurso, passamos a nos organizar e em 2015 a cerimônia foi realizada. Com parte do recurso foi comprada uma câmera para viabilizar o registro e a realização de um documentário. Panteani, filha de Tene, já participara de oficinas de vídeo e da realização de filmes de cineastas huni kuin no Jordão e vinha registrando o processo de pesquisa de seu pai e também de sua mãe que, juntamente com as demais mulheres da comunidade, estava engajada em recuperar os saberes femininos do nixpu pima. Além de auxiliá-la no registro, realizei com ela e seu pai a edição do filme Nixpu pima - Rito de iniciação Huni Kuin ${ }^{3}$.

Pesquisas como as de Vari Puyanawa (PUYANAWA, 2013), de Tadeu Siã (SIÃ, 2013), Bebito Pinhanta (PINHANTA, 2013, 2014) ou a de José Paulo Maná (MANÁ, 2013) também tinham engajado a comunidade em um processos coletivos de aprendizagem e transformação. A pesquisa de Tene, portanto, não era uma exceção. Experiências como essa, que articulam o engajamento e a transformação xamânica de três gerações de uma comunidade ao processo de realização do audiovisual colocam problemas de escrita que são importantes para que sigamos nos questionando: afinal, o que estamos chamando de pesquisa? Que escritas são essas e qual a concepção de linguagem que elas implicam?

Com Ibã aprendi que a relação entre indígenas e universidade e a ideia de "aprender a pesquisar com os brancos" não é tão simples. Ao longo dos anos trabalhando com esse pesquisador, pude me aproximar do que ele chama de "pesquisa huni kuin", nome com que se refere à pesquisa que aprendeu com seu pai. Filho de Tuin, ele cresceu imerso nos conhecimentos de cantos, mitos e rituais que seu pai guardava em sua prodigiosa memória.

\footnotetext{
${ }^{3}$ Disponível em: www.youtube.com/watch?v=5jnn01 kEuDg\&t=82s Acesso em junho de 2020.
} 
Professor desde os 18 anos, em meio a seu processo de formação e atuando junto a seus colegas na Organização de Professores Indígenas do Acre (OPIAC), Ibã se engaja no registro desses saberes, com uso de gravador e transcrição. Concentra-se, junto de seu pai e outros anciãos, nos cantos huni meka, cantos tradicionais de nixi pae (ayahuasca) do povo Huni Kuin.

Além de the ensinar essa prática musical, sua técnica vocal, o sentido oculto de sua linguagem cifrada e tudo mais a respeito desses cantos e da ciência do nixi pae, Tuin também introduz Ibã em seu próprio percurso de pesquisador huni kuin. Contando suas memórias de aprendizagem, o pai passa a lhe transmitir sua experiência junto aos mais velhos, os modos tradicionais de ensinar e aprender, os procedimentos que ele próprio foi adotando e adaptando com o tempo, a solução que deu às dificuldades de uma época em que esses saberes eram proibidos e perseguidos, o valor da memória para os Huni Kuin e as práticas para aperfeiçoá-la, os modos como estabeleceu laços de parentesco e compadrio com seus mestres, entre outras práticas. À medida que foi compreendendo o que Tuin estava the ensinando e que colocava em prática junto com outros especialistas, Ibã logo distinguiu ali, diferente da pesquisa escolar ou antropológica que conhecera entre os brancos, uma pesquisa propriamente huni kuin.

Porém, longe de um verticalismo hierarquizante, em momento algum ele chega a relacionar a especificidade dessa pesquisa ao abandono de recursos, técnicas e tecnologias dos brancos. Pelo contrário, ele sempre utilizou e estimulou o seu emprego, já que não seria a utilização desses recursos que descaracterizaria essa pesquisa huni kuin. Ibã também sempre deixou claro para seus colegas que a universidade não poderia thes "ensinar" a pesquisar como indígenas, que dependia deles construírem a pesquisa de seus povos.

Em 2012, em um debate na Universidade de São Paulo ${ }^{4}$, eu podia então compreender em que contexto ele elaborava, para uma pergunta sobre seu aprendizado em pesquisa na universidade, sua resposta: "a universidade tem que aprender comigo". Entendo que essa frase significa que a universidade ou mesmo os brancos não poderiam ter-lhe ensinado a pesquisar, que ele aprendera a pesquisar entre os huni kuin, como huni kuin, a partir dos conhecimentos, práticas e estratégias desenvolvidos por seu pai em um contexto próprio desse povo, de conhecimentos huni kuin e ainda segundo práticas de linguagem especificamente huni kuin. Portanto, não se trata de usar técnicas brancas para pesquisar saberes indígenas, mas de se apropriar desses recursos para chegar ao que ele chama de "pesquisa huni kuin".

Assim, ao longo dos anos pesquisando com Ibã, imaginava como algo dessa experiência do Mahku - Movimento dos Artistas Huni Kuin poderia contribuir para a formação de novos acadêmicos no curso. Parafraseando-o: o que a universidade poderia

\footnotetext{
${ }^{4}$ Disponível em: www.youtube.com/watch?v=3LC5pV0i354. Acesso em junho de 2020.
} 
aprender com Ibã e os pesquisadores huni kuin e de outros povos? Em 2017, com nossa participação no seminário temático "Encontro de Saberes: transversalidades e experiências" na VI ReACT- Reunião de Antropologia da Ciência e Tecnologia, tivemos a oportunidade de refletir sobre a questão da escrita e a trajetória do Mahku desde o problema da transversalidade (MATTOS; IBÃ, 2017b; MATTOS, 2017). As conexões com o fora da universidade e as transformações do coletivo foram então pensadas justamente como aquilo que faz a especificidade dessa pesquisa. Sua aliança com outras linguagens, com outros conhecimentos, com saberes não humanos, suas transformações, a incorporação da exterioridade. Definimos então três escritas: imagens, corpos e terra.

A escrita das imagens se refere inicialmente às experiências em audiovisual com a pesquisa de Ibã: registro dos huni meka e dos relatos de sua aprendizagem da pesquisa huni kuin com seu pai. A certa altura Ibã traz para o trabalho um conjunto de desenhos dos huni meka feitos por Bane, seu filho, sugerindo a produção de desenhos animados. Passamos a criar vídeos curtos para o Youtube e Facebook que combinavam a performance dos cantos sobrepostas aos desenhos com comentários a partir dessas imagens.

Visando dar continuidade a esse trabalho escrevemos um projeto para a realização de um encontro de jovens desenhistas, que aconteceu em 2011, na aldeia Mae Bena, Terra Indígena Kaxinawa Seringal Independência, Jordão, Acre. Com os desenhos realizados nesse encontro fizemos uma primeira exposição em Rio Branco e então o coletivo Mahku se constitui à medida que passam a ser convidados a participar de exposições de arte contemporânea. A partir das experiências audiovisuais com os desenhos, realizamos dois filmes sobre a trajetória do grupo: "O espírito da floresta" (2012) ${ }^{5}$, que conta a origem do coletivo desde as pesquisas de lbã, e "O sonho do nixi pae" $(2015)^{6}$, que retoma a gênese do Mahku e apresenta sua atuação nas exposições.

A escrita dos corpos se concentra nos desdobramentos do trabalho de apresentação do Mahku em eventos acadêmicos e exposições de arte. Para essas ocasiões o coletivo criou os Laboratórios de Arte e Percepção. Assim, além de apresentar e comentar seus trabalhos acadêmicos e artísticos, o coletivo realiza vivências junto ao público não indígena a partir de sua pesquisa na cultura visionária huni kuin.

A escrita da terra visa pensar como desdobramento da pesquisa huni kuin o projeto do Centro Mahku Independente, sede do grupo localizada na floresta próxima ao seu território. O Centro propõe o intercâmbio de conhecimentos via residências artísticas e outras parcerias com universidades, museus e instituições culturais, exercendo um

\footnotetext{
${ }^{5}$ Disponível em: $w$ ww.youtube.com/watch?v=zRlbRpoi0cQ\&t=955s. Acesso em junho de 2020.

${ }^{6}$ Disponível em: www.youtube.com/watch?v=SeBGft8zOuw. Acesso em junho de 2020.
} 
considerável impacto artístico e cultural entre indígenas e não indígenas da região e do estado.

Com essa noção de escrita, visávamos, portanto, restabelecer o caráter subversivo das práticas de linguagem que chamavam atenção em algumas pesquisas da Licenciatura, as quais, à medida que se apropriavam e se contrapunham à concepção de linguagem da universidade, resultavam num regime misto que colocava à prova o regime de signos majoritário da universidade ao submetê-lo, em suas práticas de escrita, à dominância relativa de seu próprio regime de signos. Esse regime de signos misto que define tal noção de escrita remete ainda ao modo como muitos desses povos concebem a escrita alfabética em associação com seus sistemas gráficos (COLLET, 2017; MACEDO, 2009; LAGROU, 2007, 2011).

\section{CONCLUSÃO}

Busquei apresentar, em um esforço de pensar a transversalidade, a relação de saberes no encontro entre universidade e acadêmicos de uma Licenciatura indígena. Рага tanto, iniciei enfocando a imagem da linguagem com a qual os acadêmicos indígenas são recebidos na universidade.

Os postulados da Linguística, conforme definidos por Deleuze e Guattari (1995), representariam bem o que buscamos apresentar como a ideia de linguagem com a qual os indígenas são confrontados na universidade. O encontro com essa noção de linguagem é precedido de uma série de outros encontros similares (e seus códigos): com os missionários (e a Bíblia), o Estado (e a Lei), a escola (e a Escrita). Na universidade, a ideia de linguagem a que são apresentados, a da Linguística, não difere dessas outras, no sentido de que compartilham uma gênese comum, mas também no sentido de que fazem parte de um mesmo regime de signos.

Os acadêmicos indígenas, ao se aliarem por sua vez com as práticas de linguagem de seu próprio regime de signos (rituais, cantos visionários, grafismos), elaboram uma outra escrita para suas pesquisas. Essas práticas de escrita não dividem com a universidade a mesma concepção de linguagem. Porém, não se trata de abandonar a escrita, como poderia supor um verticalismo hierarquizante. Pelo contrário, os acadêmicos se mostram bastante motivados em redigir suas monografias.

Essas monografias, ainda que redigidas, não são entendidas como fechadas sobre si mesmas, mas escritas em uma língua que se abre para conexões rizomáticas. A noção de escrita aqui apresentada busca chamar atenção para o modo como esses textos se baseiam numa concepção de língua que se conecta a seu fora, por meio da transformação dos corpos, 
da política com parentes animais ou plantas mestras ou da composição de pessoas coletivas (VIVEIROS DE CASTRO, 2002; CESARINO, 2012).

Assim, as dicotomias que ordenam o regime de signos da universidade (indivíduo e sociedade, natureza e cultura, realidade e representação) são postas à prova nas práticas de linguagem que servem de referência a essas pesquisas. Essas dicotomias são importantes para situar os riscos à transversalidade, visto que elas, ao redistribuírem continuamente o pensamento e a linguagem em seus termos, operam como inibidores da diferença. À medida que um regime de signos desrespeita esses marcos, opera-se constantemente um trabalho de polícia para reinstaurar a ordem ontológica.

Desse modo, busquei mostrar como a escrita da pesquisa de acadêmicos de uma licenciatura indígena, em sua continuidade e coplanaridade com as práticas desse outro regime de signos, apresenta uma concepção de linguagem diferente daquela que a universidade insiste em postular como universal.

\section{REFERÊNCIAS}

BRASIL, Ministério da Educação. Referencial Curricular Nacional para Escolas Indígenas. Brasília: MEC/SEF/DPEF, 1998.

Indígenas. Brasília: 2015.

. Resolução CNE/CP nº 01/15. Diretrizes Curriculares Nacionais para Formação de Professores

CESARINO, Pedro de Niemeyer. A escrita e os corpos desenhados: transformações do conhecimento xamanístico entre os Marubo. Revista de Antropologia - USP, v. 55, p. 75-137, 2012.

CLASTRES, Pierre. A Sociedade contra o Estado. Pesquisas de antropologia política. Tradução Theo Santiago. São Paulo, Cosac Naify, 2003.

Entre 0 silêncio e o diálogo. In: Lévi-Strauss, L'arc - Documentos, São Paulo, 1968. p. 87-90.

COLLET, Célia Letícia Gouvêa. "Quero Progresso sendo Índio": 0 princípio da interculturalidade na educação escolar indígena. Dissertação de Mestrado. Rio de Janeiro: PPGAS - Museu Nacional/UFRJ, 2001.

Ritos de civilização e cultura: a escola bakairi. Tese de doutorado. Programa de PósGraduação em Antropologia Social do Museu Nacional, UFRJ, 2006.

Máquinas de escrita: sobre a introdução da escrita alfabética pelas "escolas indígenas", Revista Polêm!ca, v. 17, n.4, p. 16-28, 2017.

DÉLÉAGE, Pierre. Lettres mortes. Essai d'anthropologie inversée. Fayard, 2017.

DELEUZE, Gilles; GUATTARI, Félix. Mil Platôs - Capitalismo e esquizofrenia 2. Vol. 2. Tradução Ana Lúcia de Oliveira e Lúcia Cláudia Leão. São Paulo: Editora 34, 1995. 
. Mil Platôs - Capitalismo e esquizofrenia 2. Vol. 5. Tradução Peter Pal Pelbart e Janice Caiafa. São Paulo: Editora 34, 1997.

. 0 Anti-Édipo - Capitalismo e esquizofrenia 1. Tradução Luiz Orlandi. - São Paulo: Ed. 34, 2010.

Mil Platôs - Capitalismo e esquizofrenia 2. Vol. 1. Tradução Aurélio Guerra e Célia Pinto Costa. São Paulo: Ed. 34, 2011.

GOLDMAN, Marcio. Alguma antropologia. Rio de Janeiro: Relume Dumará, 1999. Letras, 2006.

Como funciona a democracia: uma teoria etnográfica da política. Rio de Janeiro: Sette . Os Tambores do Antropólogo: Antropologia Pós-Social e Etnografia. Ponto Urbe. Revista do Núcleo de Antropologia Urbana da USP, v. 3, p. 1-11, 2008.

IBÃ, Isaias Sales. Nixi pae, 0 espírito da floresta. Rio Branco: OPIAC/CPI, 2006.

KENSINGER, Kenneth. A body of knowledge, or, the body knows. Expedition (Penn Museum), vol. 33, issue 3, 1991. (https://www.penn.museum/sites/expedition/a-body-of-knowledge-or-the-body-knows/).

LAGROU, Els Maria. A fluidez da forma: arte, alteridade e agência em uma sociedade amazônica (Kaxinawa, Acre). Rio de Janeiro: Topbooks, 2007.

LÉVI-STRAUSS, Claude. História de Lince. Tradução Beatriz Perrone-Moisés. São Paulo: Companhia das Letras, 1993.

LÉVI-STRAUSS, Claude. 0 pensamento selvagem. Tradução de Tânia Pellegrini. Campinas: Papirus, 2004a. Naify, 2004b.

. 0 cru e 0 cozido - Mitológicas I. Tradução Beatriz Perrone-Moisés. Rio de Janeiro: Cosac \& Mito e significado. Tradução Antonio Marques Bessa. Lisboa, Edições 70, 2010. 745-780, 2011.

Existiria uma arte das sociedades contra 0 Estado? Revista de Antropologia, v. 54, n. 2, p.

LÉVI-STRAUSS, Claude; ERIBON, Didier. De perto e de longe. Tradução Julieta Leite e Léa Mello. São Paulo, Cosac \& Naify, 2005.

MACED0, Silvia Lopes da Silva. Xamanizando a escrita: aspectos comunicativos da escrita ameríndia. Mana, vol. 15, n.2, pp. 509-528, 2009.

MANÁ, José Paulo Alfredo Kaxinawa. Músicas do Katxanawa, Ritual da fertilidade do povo Huni Kuin. Trabalho de Conclusão de Curso em Licenciatura Indígena, UFAC - Floresta, 2013. 
MATTOS, Amilton Pelegrino de. 0 que se ouve entre a opy e a escola? Corpos e vozes da ritualidade guarani. Dissertação de mestrado. Faculdade de Educação da Universidade de São Paulo, 2005.

. Entre imagens, corpos e terra: transformações do MAHKU - Movimento dos Artistas Huni Kuin. ClimaCom [Online],Campinas, v.4, n.10, p. 75-90, 2017. Disponível em: http://climacom.mudancasclimaticas.net.br/?p=7673

. Os brancos ouvem a fala da terra? A escuta na pesquisa acadêmica indígena. Eutomia Revista de Literatura e Linguística. v. 1, n. 25, p. 17-40, 2019.

Dançar a pesquisa: escrita e movimento na prática acadêmica indígena. Hawò, v. 1, p. 1-43, 2021.

MATTOS, Amilton P. IBÃ, Isaias Sales. 0 sonho do nixi pae. A arte do MAHKU - Movimento dos Artistas Huni Kuin. Revista ACENO, v. 2, n. 3, p. 59-77, 2015. https://doi.0rg/10.11606/issn.25253123.gis.2017.128974

. A Política dos artistas na Pedagogia huni kuin. In: ALBUQUERQUE, Gerson Rodrigues (Org.). Das Margens. Rio Branco: Nepan Editora, 2016a. p. 77-90.

0 MAHKU - Movimento dos Artistas Huni Kuin e outros devires-huni kuin da

Universidade. Indisciplinar, n. 2, v. 2, p. 53-76, 2016b. https://doi.org/10.11606/issn.25253123.gis.2017.128974

. Escrita da imagem, escrita do corpo, escrita da terra - A Universidade do Movimento dos Artistas Huni Kuin. Trabalho apresentado no Seminário temático: Encontro de Saberes: Transversalidades e Experiências da VI React - Reunião de Antropologia da Ciência e Tecnologia, 2017b.

PINHANTA, Valdete da Silva. Registro Artístico de Musicalidades do Ritual Piyaretsi do povo Ashenika do rio Amônia. Trabalho de conclusão de Curso em Licenciatura Indígena, UFAC - Floresta, 2013.

Musicalidade Ashaninka: os rituais do Piyaretsi e seus instrumentos. In: MONTARDO, Deise Lucy, DOMINGUEZ, Maria Eugenia. (Orgs.) Arte e sociabilidades em perspectiva antropológica. Florianópolis: Ed. da UFSC, 2014. p. 151-176.

PUYANAWA, Vari Sharanaya. Nupanare - Músicas usadas na transmissão de conhecimento Puyanawa. Trabalho de conclusão de Curso em Licenciatura Indígena, UFAC - Floresta, 2013.

SAHLINS, Marshall. A tristeza da doçura ou A antropologia nativa da cosmologia ocidental. In: Cultura na prática. Tradução Vera Ribeiro. Rio de Janeiro: Ed. UFRJ, 2007. p. 561-617.

SIÃ, Tadeu Mateus Kaxinawa. Cantos de Yube Kene: A malha da Jiboia no desenho e na música huni kuin. Trabalho de conclusão de Curso em Licenciatura Indígena, UFAC - Floresta, 2013.

TENE, Noberto Sales Kaxinawa. Nixpu pima - 0 ritual de passagem do povo Huni Kuin. Trabalho de conclusão de Curso em Licenciatura Indígena, Universidade Federal do Acre - Floresta, 2013.

UFAC - FLORESTA. Ministério da Educação. Projeto Político Pedagógico do Curso de Formação para Docentes Indígenas. UFAC, 2007. 
UFAC - FLORESTA. Projeto Pedagógico de Curso de Licenciatura Indígena. Cruzeiro do Sul: UFAC, 2015.

VARZI, Achille. "Mereology", The Stanford Encyclopedia of Philosophy. Edward N. Zalta (ed.): 2019. URL: https://plato.stanford.edu/archives/spr2019/entries/mereology/.

VIVEIROS DE CASTRO, Eduardo. A inconstância da alma selvagem, São Paulo: Cosac \& Naify, 2002. Naify, 2015.

Metafísicas canibais: Elementos para uma antropologia pós-estrutural. São Paulo: Cosac

VIVEIROS DE CASTRO, Eduardo; GOLDMAN, Marcio. Introduction to Post-Social Anthropology. HAU: Journal of Ethnographic Theory, v. 2, n. 1, p. 421-433, 2012. https://doi.org/10.14318/hau2.1.018

WAGNER, Roy. A invenção da cultura. São Paulo, Cosac Naify, 2010.

Recebido em 01 de julho de 2020. Aprovado em 01 de fevereiro de 2021. 